\title{
EVALUASI BEBAN KERJA MANUAL (STUDI KASUS UD SUMBER MAKMUR MEDAN)
}

\author{
KIMBERLY FEBRINA KODRAT \\ Program Studi Teknik Industri, Universitas Al Azhar Medan \\ Jalan Pintu Air IV No. 214 Kwala Bekala, Padang Bulan, Medan, Sumatera Utara \\ Laman: kimberlyfebrina@yahoo.co.id
}

\begin{abstract}
ABSTRAK
UD Sumber Makmur adalah salah industri rumah tangga yang memproduksi makanan ringan berupa keripik singkong dengan berbagai citra rasa dimana pada bagian packaging masih menggunakan kerja manual (fisik). Penelitian dilakukan untuk mengevaluasi beban kerja manual terhadap aktivitas yang dilaksanakan. Penelitian dilakukan terhadap 2 kelompok : kelompok A (produksi) dan kelompok B (packaging). Berdasarkan hasil penelitian diperoleh bahwa beban kerja fisik rata-rata pada 2 kelompok pekerja konstan dan termasuk ke dalam klasifikasi beban kerja ringan (light medium work). Waktu istirahat diperoleh untuk kelompok A sebesar 31 menit dan kelompok B (packaging) sebesar 45 menit.
\end{abstract}

Kata kunci: beban kerja manual, perbaikan sistem kerja, muscolusceletal

\begin{abstract}
UD Sumber Makmur is one of the home industries producing snacks especially cassava chips with various kinds of flavor. Packaging process is still performed manually through utilizing the physical power of workers. This research aims to evaluate manual workload in the particular tasks. The research object includes two groups of task which are group A (associated with production tasks) and group B (associated with packaging tasks). According to the result, it shows that average physical workload in both groups is constants and it is included in light-medium work category. The break time required by workers in group $A$ and $B$ respectively is 31 minutes and 45 minutes.
\end{abstract}

Keywords: manual workload, work system improvement, musculoskeletal

\section{PENDAHULUAN}

UD Sumber Makmur merupakan salah satu industri rumah tangga yang memproduksi keripik singkong dengan berbagai citra rasa. Selain keripik singkong, perusahaan juga menghasilkan gaplek dan mokaf. Gaplek dan mokaf ini dibuat dari hasil sisa bahan pembuat keripik singkong. Bahan baku berupa singkong dipasok dari berbagai daerah disekitar Medan. Seiring dengan tuntutan permintaan dari konsumen, perusahaan telah mengganti mesin manual dengan mesin semi otomatis dalam rangka untuk menaikkan kapasitas produksi pada bagian pengirisan singkong. Namun aktivitas pada bagian pengepakan barangjadi (packaging) masih dilakukan dengan posisi duduk di atas lantai dan menggunakan penanganan material secara manual (Manual Material Handling).

Secara umum aktivitas Manual Material Handling (MMH) dapat berupa mengangkat, menurunkan, membawa, mendorong dan menarik beban dengan tangan. Aktivitas MMH pada pekerjaan apapun berpotensi menimbulkan gangguan kesehatan khususnya yang terkait dengan nyeri punggung bawah (low back pain). Penggunan tenaga manusia sebagai pekerja sangatlah dominan terutama kegiatan penanganan material secara manual ( $\mathrm{MMH}$ ). Kelebihan MMH bila dibandingkan dengan penanganan material menggunakan alat bantu adalah fleksibilitas gerakan yang dapat dilakukan untuk beban kerja ringan. Akan tetapi aktivitas 
MMH teridentifikasi beresiko tinggi sebagai penyebab utama timbulnya cedera pada otot rangka (musculoskeletal disorders). Menurut Grandjean (1993), musculoskeletal disorders (MD) pada umumnya terjadi karena kontraksi otot yang berlebihan akibat beban kerja berat, postur kerja yang salah dan perulangan gerakan yang tinggi, serta adanya getaran terhadap keseluruhan tubuh dengan durasi pembebanan yang panjang. Tingginya tingkat cedera atau kecelakaan kerja selain merugikan secara langsung yaitu sakit yang diderita oleh pekerja, kecelakaan tersebut juga akan berdampak buruk terhadap kinerja perusahaan yaitu berupa penurunan produktivitas perusahaan, baik melalui beban biaya pengobatan yang cukup tinggi dan juga ketidakhadiran pekerja serta penurunan dalam kualitas kerja.

Penelitian yang dilakukan oleh Inayah (2001) didapat bahwa denyut nadi responden sebelum kerja sebesar $82 /$ menit sampai $86 /$ menit $(38,71 \%)$ dan perubahan denyut nadi responden sebagian besar tergolong tinggi (61\%). Denyut nadi juga mengalami peningkatan saat bekerja hingga selesai bekerja antara 1,8 - 7,62 denyut/menit dan menurun pada jam istirahat sebesar 19,66 denyut/ menit. Denyut jantung dapat berubah karena meningkatnya cardiac output (curahan jantung) yang diperlukan otot yang sedang bekerja dan karena penambahan strain pada aliran darah karena terpapar panas. Pada saat bekerja terjadi peningkatan metabolisme sel -sel otot sehingga aliran darah meningkat untuk memindahkan zat -zat makanan dari darah yang dibutuhkan jaringan otot. Semakin tinggi aktivitas maka semakin meningkat metabolisme otot sehingga curah jantung akan meningkat untuk mensuplai kebutuhan zat makanan melalui peningkatan aliran darah. Peningkatan curah jantung akan meningkatkan frekuensi denyut jantung yang akan meningkatkan denyut nadi pada akhirnya (Pulung dan Setya, 2006).

Perbaikan ergonomi, harus selalu berpusat kepada manusia pemakainya (human center). Hal tersebut dapat dilakukan melalui pendekatan partisipatori (participatory approach), sehingga seluruh komponen organisasi akan merasa terlibat, berkontribusi dan bertanggung jawab terhadap perbaikan yang dilakukan (Manuaba, 2006). Sikap kerja yang tidak fisiologis atau dengan sikap paksa akan cepat menimbulkan rasa lelah. Rasa lelah sering beristirahat sehingga jam kerja efektif berkurang yang akhirnya kinerja dan produktivitas kerja menurun. Di samping itu juga sikap kerja yang tidak fisiologis yang terlalu lama dipertahankan akan menyebabkan adanya strain (reaksi), keluhan muskuloskeletal dan menimbulkan efek negatif terhadap kesehatan.

Hasil survei awal pada UD Sumber Makmur Medan menunjukkan adanya keluhan pekerja seperti sakit pada punggung, pantat, pinggang, pundak kanan, pundak kiri, telapak tangan kiri, telapak tangan kanan, lutut kiri dan lutut kanan. Pekerja dalam melakukan aktivitas sehari-hari menggunakan peralatan yang masih sederhana dengan posisi gerak yang monoton dan berulangulang sehingga memicu resiko terjadinya musculoskeletal disorders. Oleh karena itu, diperlukan penelitian untuk menghitung besarnya konsumsi energi yang dikeluarkan sebagai akibat MMH yang terdapat di perusahaan tersebut. Berdasarkan permasalahan tersebut maka tujuan dalam penelitian ini adalah mengevaluasi beban kerja manual dan merekomendasikan waktu istirahat bagi pekerja di UD Sumber Makmur Medan.

\section{METODE}

Fisiologi adalah ilmu yang mempelajari fungsi organ tubuh manusia yang dipengaruhi oleh tekanan pada otot. Ahli fisiologi telah memikirkan sistem pekerjaan yang mengijinkan individu untuk memenuhi pekerjaan mereka tanpa dipengaruhi oleh kelelahan yang berlebihan. Dengan demikian pada saat pekerjaan berakhir, mereka tidak hanya dapat memulihkan diri dari kelelahan untuk kembali bekerja pada hari berikutnya, tetapi mereka juga akan mampu menikmati kegiatan pada saat mereka tidak bekerja. 
Kriteria fisiologi membatasi pada metabolic stress and fatigue yang berhubungan dengan beban pekerjaan angkat yang berulang-ulang (Grandjean, 1993). Aktivitas seperti berjalan, membawa beban dan mengangkat beban dengan berulang-ulang menggunakan kelompok otot yang lebih banyak daripada pekerjaan yang tidak berulang. Jenis pekerjaan tersebut membutuhkan lebih banyak energy expenditure yang tidak boleh melebihi kapasitas energi pekerja. Kriteria fisiologi menetapkan batas dari maksimum energy expenditure untuk pekerjaan angkat adalah $2,2-4,7 \mathrm{Kkal} / \mathrm{menit}$. Berat atau tingginya kerja yang harus dilakukan seorang pekerja akan bisa ditentukan oleh gejala-gejala perubahan yang tampak dan bisa diukur lewat pengukuran anggota tubuh atau fisik manusia antara lain (Wignjosoebroto, 2000):

- Laju detak jantung (heart rate)

- Tekanan darah (blood pressure)

- Temperatur badan (body temperature)

- Laju pengeluaran keringat (sweating rate)

- Konsumsi oksigen yang dihirup (oxygen consumption)

- Kandungan kimiawi dalam darah (latic acid content)

Pengukuran tingkat kelelahan kerja akibat aktivitas fisiologis selama bekerja dapat dilakukan dengan melakukan pengukuran denyut jantung, konsumsi oksigen (Molen et al., 2007), dan tekanan darah (Hsu et al., 2008; Abdelhamid and Everett, 2002). Pengukuran denyut jantung lebih mudah untuk diukur dan telah banyak dilakukan oleh peneliti, diantaranya oleh Spurr et al. (1998).

Grandjean (1998) menjelaskan bahwa salah satu pendekatan untuk mengetahui berat ringannya beban kerja adalah dengan menghitung denyut nadi kerja, konsumsi oksigen, kapasitas ventilasi paru dan suhu inti tubuh. Pada batas tertentu nadi kerja, konsumsi oksigen, kapasitas ventilasi paru dan suhu inti tubuh mempunyai hubungan linier tinggi dengan konsumsi oksigen atau pekerjaan yang dilakukan. Penilaian beban kerja dapat dilihat dari derajat beban kerja dengan menghitung denyut nadi kerja berdasarkan selisih denyut nadi saat kerja dengan denyut nadi istirahat (resting pulse). Salah satu cara yang digunakan untuk menghitung denyut nadi secara palpasi adalah dengan meraba denyut nadi kerja pada arteri radialis dan dicatat secara manual memakai jam henti (stop watch) menggunakan metode 10 denyut (Philips, 2000). Penggunaan nadi kerja untuk menilai berat ringannya beban kerja mempunyai beberapa keuntungan, lebih mudah, cepat dan murah juga tidak diperlukan peralatan yang mahal dengan hasil yang cukup reliabel. Kepekaan denyut nadi terhadap perubahan pembebanan yang diterima tubuh cukup tinggi. Denyut nadi akan segera berubah selaras dengan perubahan pembebanan, baik yang berasal dari pembebanan mekanika, fisika maupun kimiawi.

Metode penelitian menggunakan metode deskriptif dengan menggunakan rancangan penelitian cros sectional. Lokasi penelitian adalah di UD Sumber Makmur Medan. Penilaian beban kerja fisik dilakukan dengan 2 cara : 1) Penilaian beban kerja secara langsung dan 2) penilaian beban kerja secara tidak langsung. Bentuk regresi hubungan energi dengan kecepatan denyut jantung secara umum adalah regresi kuadratis dengan persamaan Murrel sebagai berikut :

$\mathrm{Y}=1,80411-0,0229038 \mathrm{X}+4,71733.10^{-4} \mathrm{X}^{2}$

Dimana:

Y : Energi (Kkal per menit)

$\mathrm{X}$ : Kecepatan denyut jantung (denyut per menit)

Setelah besaran kecepatan denyut jantung disetarakan dalam bentuk energi, maka konsumsi energi untuk kegiatan kerja tertentu bisa dituliskan dalam bentuk matematis sebagai berikut :

$\mathrm{KE}=\mathrm{E}_{\mathrm{t}}-\mathrm{E}_{\mathrm{i}}$

Dimana :

KE : Konsumsi energi untuk suatu kegiatan kerja tertentu (Kkal/menit)

$\mathrm{E}_{\mathrm{t}}$ : Pengeluaran energi pada saat waktu kerja tertentu (Kkal/menit) 
$\mathrm{E}_{\mathrm{i}}$ : Pengeluaran energi pada saat istirahat (Kkal/menit)

Jika denyut nadi dipantau selama istirahat, kerja dan pemulihan, maka recovery (waktu pemulihan) untuk beristirahat meningkat sejalan dengan beban kerja. Dalam keadaan yang ekstrim, pekerja tidak mempunyai waktu istirahat yang cukup sehingga mengalami kelelahan yang kronis:

$$
\mathrm{R}=\frac{\mathrm{T}(\mathrm{W}-\mathrm{S})}{\mathrm{W}-1,5}
$$

Dimana :

$\mathrm{R}$ : Istirahat yang dibutuhkan dalam menit (Recovery)

$\mathrm{T}$ : Total waktu kerja dalam menit

W : Konsumsi energi rata-rata untuk bekerja dalam kkal/menit

S : Pengeluaran energi rata-rata yang direkomendasikan dalam Kkal/menit (biasanya 4 atau $5 \mathrm{Kkal} /$ menit)

\section{HASIL DAN PEMBAHASAN}

Pengukuran denyut jantung pekerja di bagian proses produksi dan packaging dilakukan pada waktu awal bekerja, istirahat dan selesai bekerja. Pengukuran denyut jantung dilakukan setiap 3 jam, dengan pertimbangan efisiensi waktu kerja karena pengambilan data denyut jantung membutuhkan waktu lama sehingga dikhawatirkan akan mengganggu aktivitas pekerja. Rata-rata hasil pengukuran denyut jantung terhadap 18 orang pekerja di bagian pengirisan, pencucian dan penggorengan dengan 4 kali pengambilan dalam 1 hari dapat dilihat pada Tabel 1. Sementara itu, Tabel 2 menunjukkan rata-rata hasil pengukuran denyut jantung pada pekerja di bagian packaging.

Perbandingan hasil pengukuran denyut jantung pada pekerja kelompok A dengan kelompok $\mathrm{B}$ menunjukkan rata-rata denyut jantung kelompok B lebih besar. Hal ini disebabkan pekerja di bagian packaging melakukan aktivitas kerja secara manual dengan posisi duduk di atas lantai dan menggunakan tangan untuk memasukkan keripik singkong ke dalam kantong plastik, sehingga memicu tekanan pompa jantung lebih tinggi.

Tabel 1. Rata-rata Denyut Jantung pada Pekerja Kelompok A (pulse/menit)

\begin{tabular}{lccccc}
\hline & \multicolumn{5}{c}{ Tanggal Pengamatan } \\
\cline { 2 - 6 } & $\mathbf{0 2 / 0 8 / 1 3}$ & $\mathbf{0 3 / 0 8 / 1 3}$ & $\mathbf{0 4 / 0 8 / 1 3}$ & $\mathbf{0 5 / 0 8 / 1 3}$ & $\mathbf{0 6 / 0 8 / 1 3}$ \\
\hline 7.45 & 98 & 100 & 104 & 110 & 107 \\
10.45 & 100 & 102 & 110 & 120 & 102 \\
12.45 & 98 & 99 & 100 & 102 & 99 \\
16.45 & 100 & 99 & 99 & 100 & 99 \\
$\mathrm{X}$ & 99 & 100 & 103,25 & 108 & 101,75 \\
\hline
\end{tabular}

Tabel 2. Rata-rata Denyut Jantung pada Pekerja Kelompok B (pulse/menit)

\begin{tabular}{cllllc}
\hline \multirow{2}{*}{ Jam } & \multicolumn{5}{c}{ Tanggal Pengamatan } \\
\cline { 2 - 6 } & $\mathbf{0 2 / 0 8 / 1 3}$ & $\mathbf{0 3 / 0 8 / 1 3}$ & $\mathbf{0 4 / 0 8 / 1 3}$ & $\mathbf{0 5 / 0 8 / 1 3}$ & $\mathbf{0 6 / 0 8 / 1 3}$ \\
\hline 7.45 & 105 & 98 & 97 & 104 & 112 \\
10.45 & 120 & 102 & 110 & 120 & 120 \\
12.45 & 107 & 100 & 97 & 116 & 106 \\
16.45 & 100 & 99 & 102 & 110 & 105 \\
$\mathrm{X}$ & 108 & 99,75 & 101,5 & 112,5 & 110,75 \\
\hline
\end{tabular}


Tabel 3. Konsumsi Energi pada Pekerja Kelompok A (Kkal/menit)

\begin{tabular}{cccccc}
\hline \multirow{2}{*}{ Jam } & \multicolumn{5}{c}{ Tanggal Pengamatan } \\
\cline { 2 - 6 } & $\mathbf{0 2 / 0 8 / 1 3}$ & $\mathbf{0 3 / 0 8 / 1 3}$ & $\mathbf{0 4 / 0 8 / 1 3}$ & $\mathbf{0 5 / 0 8 / 1 3}$ & $\mathbf{0 6 / 0 8 / 1 3}$ \\
\hline 7.45 & 4,09 & 4,23 & 4,52 & 4,99 & 4,75 \\
10.45 & 4,23 & 4,37 & 4,99 & 5,84 & 4,37 \\
12.45 & 4,09 & 4,16 & 4,23 & 4,37 & 4,16 \\
16.45 & 4,23 & 4,16 & 4,16 & 4,23 & 4,16 \\
X & 4,16 & 4,23 & 4.48 & 4.95 & 4.36 \\
\hline
\end{tabular}

Tabel 4. Konsumsi Energi pada Pekerja Kelompok B (Kkal/menit)

\begin{tabular}{cccccc}
\hline Jam & \multicolumn{5}{c}{ Tanggal Pengamatan } \\
\cline { 2 - 6 } & $\mathbf{0 2 / 0 8 / 1 3}$ & $\mathbf{0 3 / 0 8 / 1 3}$ & $\mathbf{0 4 / 0 8 / 1 3}$ & $\mathbf{0 5 / 0 8 / 1 3}$ & $\mathbf{0 6 / 0 8 / 1 3}$ \\
\hline 7.45 & 4,60 & 4,09 & 4,02 & 4,52 & 5,15 \\
10.45 & 5,84 & 4,37 & 4,99 & 5,84 & 5,84 \\
12.45 & 4,75 & 4,23 & 4,02 & 5,49 & 4,67 \\
16.45 & 4,23 & 4,16 & 4,37 & 4,99 & 4,60 \\
X & 4.85 & 4,21 & 4,35 & 5,21 & 5,06 \\
\hline
\end{tabular}

Tabel 5. Waktu Istirahat bagi Pekerja Kelompok A (menit)

\begin{tabular}{rrrrrr}
\hline \multirow{2}{*}{ Jam } & \multicolumn{5}{c}{ Tanggal Pengamatan } \\
\cline { 2 - 6 } & $\mathbf{0 2 / 0 8 / 1 3}$ & $\mathbf{0 3 / 0 8 / 1 3}$ & $\mathbf{0 4} / \mathbf{0 8} / \mathbf{1 3}$ & $\mathbf{0 5 / 0 8 / 1 3}$ & $\mathbf{0 6 / 0 8 / 1 3}$ \\
\hline 7.45 & 2,08 & 5,05 & 10,33 & 17,02 & 13,8 \\
10.45 & 5,05 & 7,73 & 17,02 & 25,43 & 7,73 \\
12.45 & 2,08 & 3,50 & 5,05 & 7,73 & 3,50 \\
16.45 & 5,05 & 3,50 & 3,50 & 5,05 & 3,50 \\
Total & 14,26 & 19,78 & 35,90 & 55,23 & 28,53 \\
\hline
\end{tabular}

Tabel 6. Hasil Evaluasi Waktu Istirahat bagi Pekerja Kelompok B (menit)

\begin{tabular}{rccccc}
\hline \multirow{2}{*}{ Jam } & \multicolumn{5}{c}{ Tanggal Pengamatan } \\
\cline { 2 - 6 } & $\mathbf{0 2 / 0 8 / 1 3}$ & $\mathbf{0 3 / 0 8 / 1 3}$ & $\mathbf{0 4 / 0 8 / 1 3}$ & $\mathbf{0 5 / 0 8 / 1 3}$ & $\mathbf{0 6 / 0 8 / 1 3}$ \\
\hline 7.45 & 11,61 & 2,08 & 0,47 & 10,33 & 18,90 \\
10.45 & 25,43 & 7,73 & 17,02 & 25,43 & 7,73 \\
12.45 & 13,85 & 5,05 & 0,5 & 22,40 & 12,68 \\
16.45 & 5,05 & 3,50 & 7,73 & 17,02 & 11,61 \\
Total & 55,94 & 18,36 & 25,72 & 75,18 & 50,92 \\
\hline
\end{tabular}


Pengukuran konsumsi energi dihitung berdasarkan rata-rata denyut jantung yang telah diperoleh menggunakan rumus pada persamaan 2. Hasil perhitungan dapat dilihat pada Tabel 3 dan 4 .

Kelompok A (pekerja di bagian pengirisan, pencucian dan penggorengan) menggunakan energi lebih sedikit dibanding dengan kelompok B (pekerja di bagian packaging), karena pekerja pada bagian pengirisan singkong sudah menggunakan mesin semi otomatis sehingga pekerjaannya lebih ringan.

Lama waktu istirahat yang dibutuhkan oleh pekerja untuk memulihkan kondisi tubuhnya diperoleh dengan menggunakan persamaan 3 berdasarkan konsumsi energi yang telah diperoleh pada Tabel 3 dan 4. Hasil perhitungan rata-rata waktu istirahat kedua kelompok kerja di UD. Sumber Makmur ditunjukkan pada Tabel 5 dan 6. Dari perhitungan, diusulkan waktu istirahat yang diperlukan 31 menit untuk pekerja kelompok A dan 45 menit untuk pekerja kelompok B.

Istirahat ini dilakukan diluar jadwal istirahat formal. Pekerja melakukan pekerjaan pengirisan dan penggorengan secara bergiliran. Usulan waktu istirahat dilakukan dengan cara menukar posisi pekerja pengirisan dengan pekerja penggorengan selama 31 menit dimulai dari jam 12.15 hingga jam 13.16, selanjutnya pekerja pada kelompok A kembali pada posisi kerja awal. Sementara itu, kelompok B diusulkan untuk memulai waktu istirahat dari jam 12.20 hingga 13.25 secara bergantian.

\section{SIMPULAN}

Beban kerja pada kelompok A dan B termasuk dalam golongan klasifikasi ringan. Perhitungan waktu istirahat untuk kelompok A sebesar 31 menit dan kelompok B sebesar 45 menit dimana istirahat dilakukan diluar jadwal istirahat formal dengan cara nenukar posisi pekerja.

\section{DAFTAR PUSTAKA}

Abdelhamid, T.S., and Everett, J.E., 2002. Physiological Demands during Construction Work, EBSCO, 427-437

Grandjean, E. , 1993. Fitting the Task to The Man, 4 th Ed, London.

Grandjean, E., 1998. Fitting the Task to The Man : A Textbook of Occupational Ergonomics Taylor and Francis Ltd., London.

Hsu, D.J., Sun, Y.M., Chuang, K.H., Juang,Y.J., and Chang, F.L., 2008. Effect of Elevation Change on Work Fatigue and Physiological Symptoms for High-Rise Building Construction Workers, Safety Science Elsevier, 46, 833-843

Inayah, Z., 2001. Hubungan Status Gizi, Intake Cairan, dan Beban Kerja terhadap Respon Fisiologi Tenaga Kerja : Studi Kasus di Bagian Fabrikasi dan Foundry Divisi Peralatan Industri PT. BOMA BISMA INDRA (Persero) Pasuruan, Skripsi, Universitas Airlangga, Surabaya.

Manuaba, A. 2006. A Total Approach in Ergonomics is must To Attain Humane, Competitive and Sustainable Work System and Products, Proceeding Ergo Future 2006: International Symposium On Past, Present And Future Ergonomics, Occupational Safety and Health, 1-6.

Molen, V.D., Sluitera, J.K., and Frings-Dresena, M.H. 2007. Behavioral Change Phases of Different Stakeholders Involved in The Implementation Process, Applied Ergonomics Elsevier, 448-459

Phillips, C.A. 2000. Human Factors Engineering, John Wiley and Sons Inc., New York.

Pulung, S dan Setya, I.P. 2006. Perbedaan Efek Fisiologis pada Pekerja Sebelum dan Sesudah Bekerja di lingkungan Kerja Panas, Jurnal Kesehatan Lingkungan, (2) 2, 163-172

Spurr, G.B., Prentice, A.M., Murgatroyd, P.R., Goldberg, G.R., Reina, J.C., and Christman, N.T., 1998. Energy Expenditure from Minuteby Minute Heart-Rate Monitoring: Comparison with Indirect Clorimetry, American Journal of Clinical Nutrition, 48, 552-559.

Sutalaksana, I.Z., Anggawisastra R., dan Tjakraatmadja, J.H., 2006. Teknik Perancangan Sistem Kerja, Penerbit ITB, Bandung. 